Provided for non-commercial research and education use. Not for reproduction, distribution or commercial use.

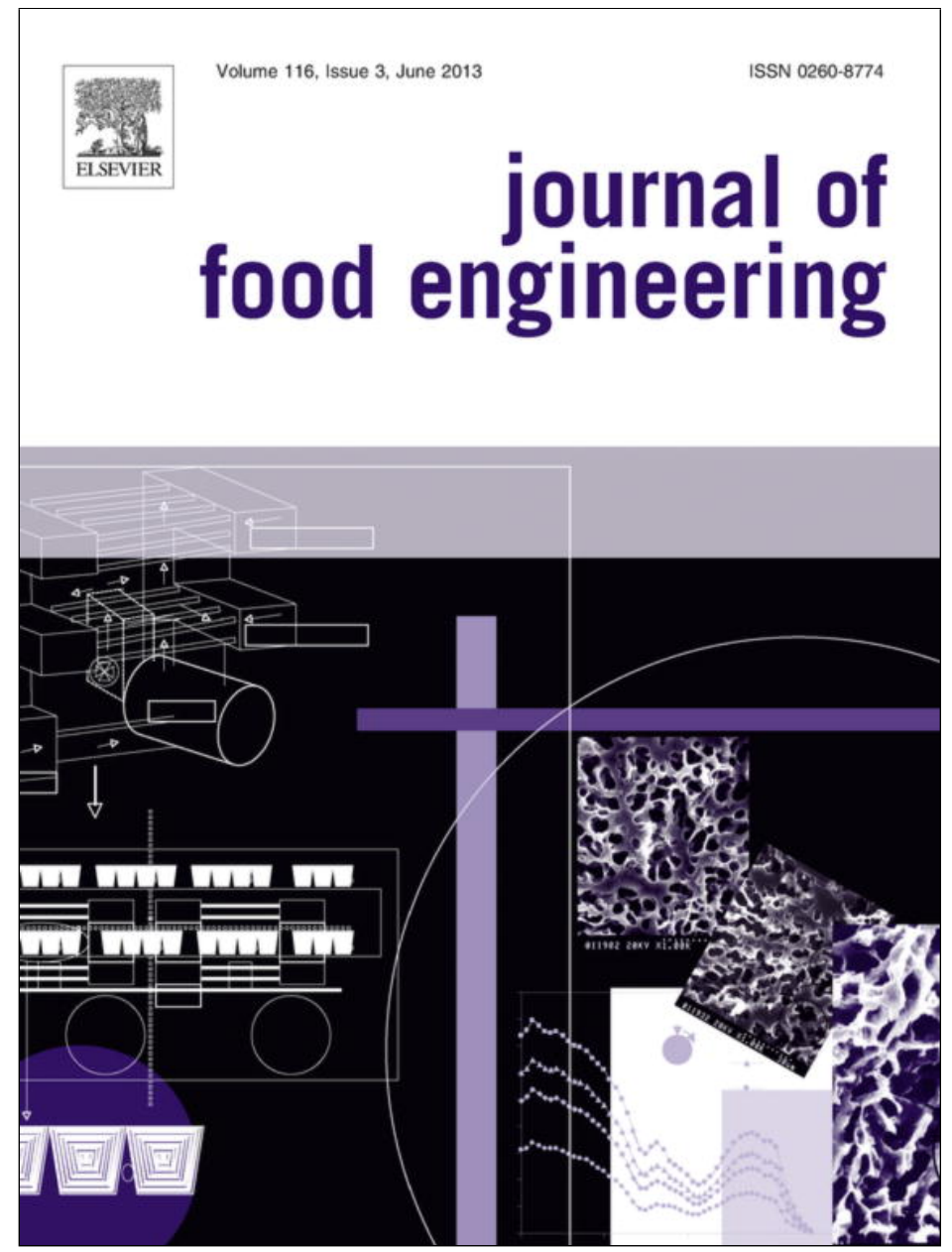

This article appeared in a journal published by Elsevier. The attached copy is furnished to the author for internal non-commercial research and education use, including for instruction at the authors institution and sharing with colleagues.

Other uses, including reproduction and distribution, or selling or licensing copies, or posting to personal, institutional or third party websites are prohibited.

In most cases authors are permitted to post their version of the article (e.g. in Word or Tex form) to their personal website or institutional repository. Authors requiring further information regarding Elsevier's archiving and manuscript policies are encouraged to visit:

http://www.elsevier.com/copyright 


\title{
Transport mechanism of macromolecules on hydrophilic bio-polymeric matrices - Diffusion of protein-based compounds from chitosan films
}

\author{
Ana C. Pinheiro ${ }^{a}$, Ana I. Bourbon ${ }^{a}$, António A. Vicente ${ }^{\mathrm{a}, *}$, Mafalda A.C. Quintas ${ }^{\mathrm{a}, \mathrm{b}}$ \\ ${ }^{a}$ IBB - Institute for Biotechnology and Bioengineering, Centre for Biological Engineering, Universidade do Minho, Campus de Gualtar, 4710-057 Braga, Portugal \\ ${ }^{\mathrm{b}}$ CBQF/Escola Superior de Biotecnologia, Rua Dr. Antonio Bernardino de Almeida, 4200-072 Porto, Portugal
}

\section{A R T I C L E I N F O}

\section{Article history:}

Received 10 May 2012

Received in revised form 21 December 2012

Accepted 24 December 2012

Available online 11 January 2013

\section{Keywords:}

Mathematical models

Controlled release

Fick diffusion

Relaxation transport

Anomalous behavior

\begin{abstract}
A B S T R A C T
The transport mechanism of protein-based bioactive compounds (a peptide fraction from whey protein concentrate, glycomacropeptide and lactoferrin), from chitosan films to liquid medium, was studied. Mathematical models were used to discuss the transport mechanism. Data from release experiments was successfully described by a model which accounts for both Fick and Case II transport - the linear superimposition model. Results show that the mechanism of transport and the effect of temperature and peptide type could be related with physical properties of chitosan films where the tested bioactive compounds were incorporated. The approach presented here allows interpretation of the phenomena involved in mass transport in the systems studied and, once extended to other systems, may contribute to an understanding of transport in hydrophilic bio-polymeric matrices.
\end{abstract}

(C) 2012 Elsevier Ltd. All rights reserved.

\section{Introduction}

Environmental concerns, the increasing cost of raw materials and public awareness on environmental issues led to an increase of research on the use of biodegradable polymers from renewable sources to replace synthetic materials. These materials are mainly applied in: (i) the development of controlled drug release systems (Kakizawa et al., 2010) - biocompatibility and toxicological safety are also important features of such materials (Parveen and Sahoo, 2008) and (ii) packaging of foods (Park, 1999; Rojas-Graü et al., 2009) - the more recent concept of "active packaging" (Buonocore et al., 2003) also captured the attention of packaging scientists to controlled release of active substances from polymeric systems.

Pure diffusion, polymer matrix swelling, polymer erosion and degradation are mechanisms that lead to compound release from polymeric devices (Faisant et al., 2002; Jain, 2000; Polakovic et al., 1999). Depending on both the system (polymer/active compound) and environmental conditions, a different mechanism may prevail.

Understanding the different release mechanism may be crucial for product development and its potential applications: for instance, structure of the polymeric network - like crystallinity or film thickness - is expected to influence transport phenomena.

Literature reports diffusion of antimicrobials (Del Nobile et al., 2008; Flores et al., 2007), antioxidants (Heirlings et al., 2004; Siró

\footnotetext{
* Corresponding author. Tel.: +351253 604419; fax: +351253678986.

E-mail address: avicente@deb.uminho.pt (A.A. Vicente).
}

et al., 2006) and drugs (Liu et al., 1995; Siepmann et al., 2002) from bio-polymeric films to liquid media; and some works have reported diffusion of molecules in solid polymeric matrices, recurring to techniques such as fluorescence recovery after photobleaching (FRAP) (Hagman et al., 2010; Karbowiak et al., 2006). However, few data can be found on transport properties of molecules such as bioactive peptides and proteins, especially in liquid media. Moreover, investigation of the relationship between the films physical properties and the release behavior is seldom reported.

Bioactive peptides and proteins can present a diverse range of biological activities, namely: (i) the hydrolysates produced from whey protein concentrate (WPC) show antihypertensive properties (Mullally et al., 1997), (ii) glycomacropeptide (GMP), a peptide derived from k-casein, exhibits antibacterial activity, modulates the immune system responses and regulates blood circulation (Thomä-Worringer et al., 2006) or (iii) lactoferrin, a glycoprotein, shows antimicrobial, anti-inflammatory and anticancer activities (González-Chávez et al., 2009). Chitosan, a natural polysaccharide obtained by deacetylation of chitin, has been proved to be nontoxic, biodegradable, and biocompatible and has been extensively used to produce biodegradable films for both food (Bégin and Van Calsteren, 1999; Souza et al., 2009) and medical applications (Shi et al., 2009; Shu et al., 2001).

Due to its excellent properties chitosan is often used as carrier for bioactive compounds (Pranoto et al., 2005; Siripatrawan and Harte, 2010) and since it is edible it may be applied on food products and consumed by humans. It is thus important to understand 
the transport behavior of bioactive compounds during digestion. The research reported in this paper is a preliminary study of diffusion in liquid media at different isothermal conditions and aims at unraveling the transport mechanism in chitosan films used as carriers for protein-based bioactive compounds. Mathematical models were used to discuss the transport mechanism. The phenomena observed were discussed against the previously determined physical properties of the films (Bourbon et al., 2011).

\subsection{Theoretical considerations}

1.1.1. Mass transport phenomena in hydrophilic polymeric matrices

When immersed in liquid media, hydrophilic polymers gradually start to hydrate, causing relaxation of the polymer chain with consequent volume expansion, i.e. swelling, and therefore this will influence the transport mechanism of compounds from the polymeric matrix (Berens and Hopfenberg, 1978; Flores et al., 2007; Siepmann et al., 2002).

Then, the mechanisms associated with mass transport in polymeric systems may be generally classified as of three different types: ideal Fickian diffusion; anomalous behavior and Case II transport.

Fickian diffusion involves a substantially stochastic phenomenon (related to Brownian motion), in which the penetrant flow is exclusively driven by a concentration gradient. Case II transport, describes behavior where compound release is due to a relaxation phenomenon driven by the distance of the local system from the equilibrium. Anomalous diffusion is used to identify behaviors departing from Fickian and Case II transport (Del Nobile et al., 1994).

The relative contribution of diffusion and relaxation can be affected by the dimensions of a polymer specimen (Vrentas et al., 1975). Also, such relative contribution may be affected by environmental conditions, like temperature and concentration interval in a given penetrant/polymer pair (Berens and Hopfenberg, 1978). For biopolymers incorporated with protein-based materials - typically constituted of crystalline and amorphous phases - the film microstructure will also affect the transport mechanism (Vesely, 2008).

\subsubsection{Modelling mass transport in polymeric matrices}

In order to assess the transport properties of the active ingredient inside the polymeric matrix, it is important to use mathematical models that describe the physical mechanism without unnecessary mathematical complexity (Bates and Watts, 1988). This can be done on the basis of experimental data observation and fitting procedures. Several authors have proposed mathematical relationships to describe compound release from a hydrophilic polymer (Berens and Hopfenberg, 1978; Peppas and Sahlin, 1989).

To account for both Fickian and Case II transport effects on the observed anomalous behavior in hydrophilic matrices, a linear superimposition of both mechanisms can be used (Berens and Hopfenberg, 1978). This approach was applied in studies of transport properties of tapioca starch (Flores et al., 2007), of agarose gels (Sebti et al., 2004) and in the studies of the kinetic sorption behavior of gases in films (Visser and Wessling, 2007).

The linear superimposition approach assumes that the observed transport of molecules within the polymer can be described by the sum of the molecules transported due to Brownian motion with the molecules transported due to polymer relaxation (Berens and Hopfenberg, 1978):

$M_{t}=M_{t . F}+M_{t, R}$

where $M_{t, F}$ and $M_{t, R}$ are the contributions of the Fickian and relaxation processes, respectively, at time $t$.

Mass transport related to Brownian motion in a thin slab of polymer immersed in a sufficiently large amount of water, can be described by the solution of Fick's second law for a plane sheet with constant boundary conditions (Crank, 1975). As for polymer relaxation, it is driven by the swelling ability of the polymer, i.e. by the configuration of the system at any given time related to the configuration of the maximum swelled matrix (i.e. at equilibrium). The relaxation process is then related to the dissipation of stress induced by the entry of the penetrant and can be described as a distribution of relaxation times, each following a first ordertype kinetic equation (Berens and Hopfenberg, 1978). Hence, compounds release from a hydrophilic polymer slab can be described by:

$$
\begin{aligned}
M_{t}= & M_{\infty, F}\left[1-\frac{8}{\pi^{2}} \sum_{n=0}^{\infty} \frac{1}{(2 n+1)^{2}} \exp \left(-(2 n+1)^{2} k_{F} t\right)\right] \\
& +\sum_{i} M_{c o, R_{i}}\left[1-\exp \left(-k_{R_{i}} t\right)\right]
\end{aligned}
$$

where $k_{F}$ and $k_{R}$ are Fickian diffusion and relaxation rate constants, respectively.

In order to evaluate the physical mechanisms involved in the bioactive compounds release it is necessary to use a model that successfully describes the individual contributions of the diffusion and the relaxation processes.

Using the appropriate modification, the "general" model (Eq. (2)) can then be used to describe pure Fickian $\left(M_{\infty, F} \neq 0\right.$ and $i=0)$; anomalous $\left(M_{\infty, F}\right.$ and $\left.i \neq 0\right)$ or Case II $\left(M_{\infty, F}=0\right.$ and $\left.i \neq 0\right)$ transport.

\section{Experimental section}

\subsection{Experimental procedures}

\subsubsection{Protein-based bioactive compounds}

Three bioactive compounds were incorporated into chitosan films: a peptide fraction hydrolyzed from whey protein concentrate (WPC), glycomacropeptide (GMP) and lactoferrin. The peptide fraction was obtained from hydrolysis of WPC according to Bourbon et al. (2011). Commercial GMP and lactoferrin were obtained from Davisco Food International, Inc. (Le Sueur, USA) and DMV International (USA), respectively.

\subsubsection{Preparation of chitosan films with incorporated bioactive compounds}

Chitosan edible films were prepared by dissolving $2 \%(\mathrm{w} / \mathrm{v})$ chitosan (90\% deacetylation, Aqua Premier Co., Thailand) in a $1 \%$ lactic acid (Merck, Germany) solution and stirred, at room temperature, until the chitosan was completely dissolved. Glycerol at $1 \%$ $(\mathrm{w} / \mathrm{v})$ (Panreac, Spain) and Tween 80 at $0.2 \%(\mathrm{w} / \mathrm{v})$ (Acros Organics, Belgium) were added to plasticize the film. The $\mathrm{pH}$ of the film forming solution was 4.5 .

The bioactive compounds were incorporated into chitosan filmforming solutions at a concentration of $1 \%$ (dry basis). In order to obtain films with a similar thickness, a constant amount $(28 \mathrm{ml})$ of the chitosan solutions was casted in $8.5 \mathrm{~cm}$ plates and dried in an oven at $35^{\circ} \mathrm{C}$, overnight. The films were stored at $20^{\circ} \mathrm{C}$ (controlled by laboratory air conditioning system) and 53\% RH (obtained by equilibration in a dessicator with a saturated salt solution of $\mathrm{Mg}\left(\mathrm{NO}_{3}\right)_{2}$, under vacuum), until further use. The dried films were peeled intact from the casting plates.

\subsubsection{Determination of peptides and proteins release kinetics}

The produced peptide-containing films were cut in $2 \mathrm{~cm} \times 2 \mathrm{~cm}$ squares. The squares obtained from three films, weighting approximately $3.2 \mathrm{~g}$, were immersed into an appropriated amount of distilled water $(1: 100)$, at a constant temperate $\left(4,16,25^{\circ} \mathrm{C}\right)$, under moderate stirring (300 rpm). Release kinetics was evaluated by 
monitoring the concentration of the bioactive compounds in the surrounding solution until an equilibrium value was reached. The concentration of peptides and proteins was assessed by measuring the absorbance (Elisa Biotech Synergy HT, USA) at $280 \mathrm{~nm}$ for WPC hydrolysates and lactoferrin (Liang and Bowen, 2005) and $230 \mathrm{~nm}$ for GMP (Nakajima et al., 2005). For each experimental condition, at least three true replicates were conducted.

\subsection{Statistical procedures}

\subsubsection{Non-linear regression analysis}

The linear superimposition model (Eq. (2)) was modified and fitted to the experimental data by non-linear regression analysis, using a package of STATISTICA ${ }^{\mathrm{TM}}$ v 7.0 (Statsoft. Inc., USA). The Levenberg-Marquardt algorithm for the least squares function minimization was used.

The modifications of Eq. (2) were aimed at mathematical simplification and accurate description of the physical phenomena involved in the transport form the matrix to the liquid media:

The diffusion of part of the compounds by Fickian behavior was always assumed part of the mechanism (i.e. $M_{\infty, F}$ was always $\neq 0$ ). As a first approach, only the first term of the series was used $(n=0)$. The estimated $k$ values lead to Fourier numbers $>0.2$ (Rathore and Kapuno, 2011), - results not shown - indicating that this was a correct approximation and hence used in all regressions.

As for the relaxation part of the model $\left(M_{t, R}\right)$, it was modified depending on the tested transport mechanism: (i) assuming that transport was due only to concentration gradient and chitosan film relaxation had no effect on the transport mechanism (i.e. Fick's behavior; $i=0$ ); (ii) transport was due to the sum of concentration gradient and one main type of relaxation of the film $(i=1)$; and (iii) there was a contribution of Fick's diffusion and two different types of polymer relaxation for the release of compounds from the film $(i=2)$.

The quality of the regressions was evaluated on the basis of the determination coefficient, $R^{2}$, the squared root mean square error, RMSE (i.e., the square root of the sum of the squared residues (SSEs) divided by the regression degrees of freedom) and residuals visual inspection for randomness and normality. $R^{2}$ and SSE were obtained directly from the software. Adjusted $R^{2}$ was also calculated in order to account for the number of explanatory terms when comparing different models.

The precision of the estimated parameters was evaluated by the Standardized Halved Width (SHW\%), which was defined as the ratio between the 95\% Standard Error (obtained from the software) and the value of the estimate.

\section{Results and discussion}

\subsection{Mathematical modelling of active compounds release from} hydrophilic thin films

Accurate mathematical modelling of transport phenomena is important for the design of packaging systems and of bioactive compound carriers, since it may allow predicting behavior during shelf-life and product preparation or consumption. In this work, we studied the description of experimentally obtained data by linear superimposition model.

As described above, the linear superimposition model (Eq. (2)) was modified to assume different physical mechanisms of transport and fitted to the experimental data. Fig. 1 shows an example of model description for the three cases. It can be observed that Fick's behavior alone $(i=0)$ is unable to describe the experimental data and, hence, the physical mechanism of the transport phenomena involved here.
As for anomalous transport considering one main relaxation $(i=1)$ or two relaxations $(i=2)$, both models were able to predict the experimentally observed behavior (Fig. 1). Tables $1 \mathrm{a}$ and $1 \mathrm{~b}$ show the results of fitting Eq. (2) to the experimental data (considering one main relaxation, $i=1$ and two governing relaxations, $i=2$ ). Both models presented similar residues distribution, showing compliance with regression analysis underlying assumptions (Bates and Watts, 1988) - results not shown.

From a mathematical point a view, the model considering two relaxations presents a better regression result: adjusted $R^{2}$ are up to $7.5 \%$ higher compared with the adjusted $R^{2}$ for the model with one relaxation and RMSE is reduced up to $40 \%$. However, the quality of estimated parameters - evaluated by SHW (\%) - worsens for the model with two relaxations. Moreover, as for the model description of the transport phenomena, model $i=2$ leads to parameters without physical meaning, e.g. estimated mass released by Fickian process of lactoferrin at $16^{\circ} \mathrm{C}$ is a negative value. The quality of estimated parameters in both models could be improved if different regression approaches were to be used.

However, for comparison purposes of both models $(i=1$ and $i=2$ ) this information is sufficient - developing strategies for confidence interval minimization was out of the scope of this research.

Such strategies generally include not presenting the total mass released, but reporting $M_{t} / M_{\infty}$ (Brandao et al., 2001). However, understanding the effect of environmental conditions on the total mass released from a system can be of utmost importance when considering toxicological effects of accumulation of bioactive compounds (Bailey, 1983).

These results, together with the "less complexity rule" of mathematical modelling, allow concluding that mass transport of these protein-based compounds through chitosan films is essentially governed by anomalous behavior and that only one main relaxation, influencing transport, occurs in the polymeric matrix.

\subsection{Transport phenomena of active compounds release from hydrophilic thin films}

The accurate mathematical description of compounds release from chitosan films also allows an interpretation of the physical phenomenon based on estimated parameters. Fig. 2 shows the main tendencies of estimated parameters (from Eq. (2), for $i=1$ ) with both temperature and type of peptide.

Regarding the Fickian component of the transport, it can be observed that the total mass released via Fick's transport $\left(M_{\infty, F}\right)$, increases with increasing temperature (Fig. 2a). As for the effect of peptide type on the mass released via Fick's transport, we can observe a tendency for decreasing the total mass released with increasing peptide molecular weight (Table 2 ).

Fickian rate of diffusion, $k_{F}$, increased with temperature (Fig. 2b) but it was not possible to observe and Arrhenius type dependency. However, main tendencies allow inferring that with peptides' decreasing molecular weight, a sharper effect of temperature is observed for this parameter. Similar results have been described in literature, where diffusion rate constant $(k)$ of acetic acid and propionic acid from chitosan films increased with temperature, following in that case an Arrhenius-type dependency (Ouattara et al., 2000): Higher activation energy was obtained for acetic acid (lower molecular weight), i.e. the sensitivity to temperature increase was lower in higher molecular weight compounds (the propionic acid).

As for the relaxation component of transport, relaxation rate of diffusion $\left(k_{R_{1}}\right)$, was constant with temperature and similar for the different peptides (Fig. 2d). This should be expected since this is a property of the polymer and not of the molecule diffusing the polymer (Vrentas et al., 1975). As for the mass released via relaxation $\left(M_{\infty, R_{1}}\right)$, different behavior for the different peptides was ob- 


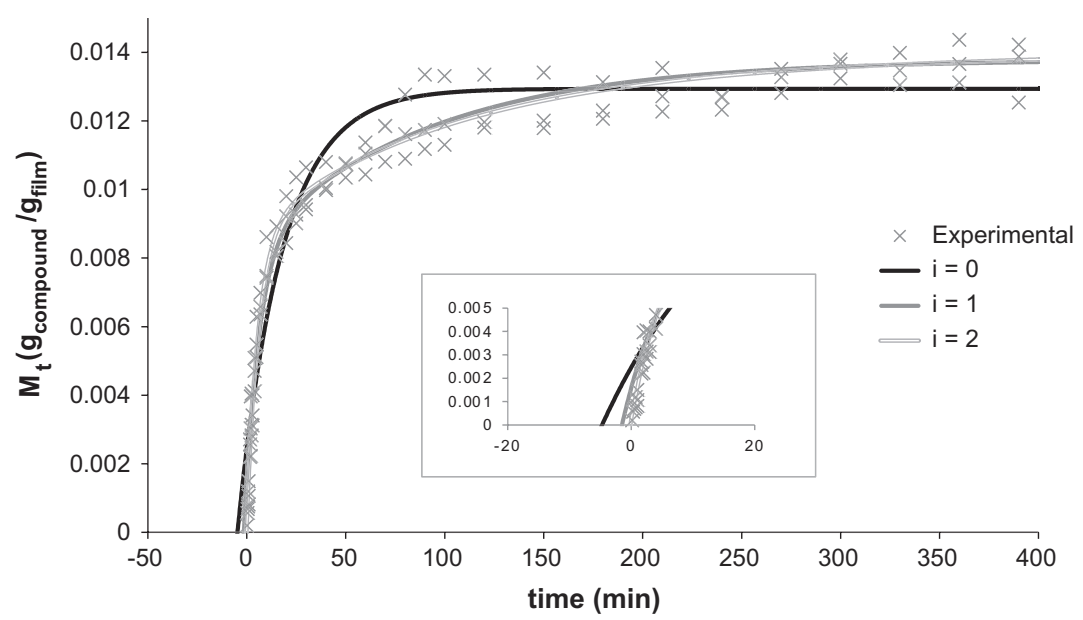

Fig. 1. Linear superimposition model description of isothermal compound release from chitosan films (example is for GMP at $4{ }^{\circ} \mathrm{C}$ ). Inset shows the detail of the model fitting to the initial experimental data.

Table 1a

Fitting the linear superimposition model (LSM) (modified Eq. (2)) to experimental data: quality of the regression on the basis of RMSE and $R^{2}$.

\begin{tabular}{|c|c|c|c|c|c|}
\hline \multirow[t]{2}{*}{ Bioactive compound } & \multirow[t]{2}{*}{ Temp. $\left({ }^{\circ} \mathrm{C}\right)$} & \multicolumn{2}{|c|}{ LSM - one relaxation $(i=1)$} & \multicolumn{2}{|c|}{ LSM - two relaxations $(i=2)$} \\
\hline & & $R^{2}$ adj & RSME & $R^{2}$ adj & RSME \\
\hline \multirow[t]{3}{*}{ Peptide fraction from WPC } & 4 & 0.977 & $2.09 \times 10^{-3}$ & 0.976 & $2.12 \times 10^{-3}$ \\
\hline & 16 & 0.969 & $2.80 \times 10^{-3}$ & 0.974 & $2.59 \times 10^{-3}$ \\
\hline & 25 & 0.981 & $2.67 \times 10^{-3}$ & 0.987 & $2.21 \times 10^{-3}$ \\
\hline \multirow[t]{3}{*}{ GMP } & 4 & 0.969 & $7.61 \times 10^{-4}$ & 0.979 & $6.27 \times 10^{-4}$ \\
\hline & 16 & 0.941 & $2.01 \times 10^{-3}$ & 0.946 & $1.92 \times 10^{-3}$ \\
\hline & 25 & 0.878 & $3.97 \times 10^{-3}$ & 0.944 & $2.37 \times 10^{-3}$ \\
\hline \multirow[t]{3}{*}{ Lactoferrin } & 4 & 0.979 & $4.94 \times 10^{-4}$ & 0.979 & $4.91 \times 10^{-4}$ \\
\hline & 16 & 0.990 & $7.16 \times 10^{-4}$ & 0.994 & $5.61 \times 10^{-4}$ \\
\hline & 25 & 0.969 & $1.22 \times 10^{-3}$ & 0.971 & $1.17 \times 10^{-3}$ \\
\hline
\end{tabular}

Table 1b

Fitting the linear superimposition model (LSM) (modified Eq. (2)) to experimental data: estimated parameters and evaluation of estimate precision using the SHW\% (in parentheses).

\begin{tabular}{|c|c|c|c|c|c|c|c|c|c|c|c|}
\hline \multirow[t]{2}{*}{ Bioactive compound } & \multirow{2}{*}{$\begin{array}{l}\text { Temp. } \\
\left({ }^{\circ} \mathrm{C}\right)\end{array}$} & \multicolumn{4}{|c|}{ LSM - one relaxation $(i=1)$} & \multicolumn{6}{|c|}{ LSM - two relaxations $(i=2)$} \\
\hline & & $\begin{array}{l}M_{\infty, F} \\
(\mathrm{~g} / \mathrm{g} \text { film })\end{array}$ & $k_{F}\left(\mathrm{~s}^{-1}\right)$ & $\begin{array}{l}M_{\infty, R_{1}} \\
(\mathrm{~g} / \mathrm{g} \text { film })\end{array}$ & $k_{R_{1}}\left(\mathrm{~s}^{-1}\right)$ & $\begin{array}{l}M_{\infty, F} \\
\text { (g/g film) }\end{array}$ & $k_{F}\left(\mathrm{~s}^{-1}\right)$ & $\begin{array}{l}M_{\infty, R_{1}} \\
\text { (g/g film) }\end{array}$ & $k_{R_{1}}\left(\mathrm{~s}^{-1}\right)$ & $\begin{array}{l}M_{\infty, R_{2}} \\
\text { (g/g film) }\end{array}$ & $k_{R_{2}}\left(\mathrm{~s}^{-1}\right)$ \\
\hline $\begin{array}{l}\text { Peptide fraction from } \\
\text { WPC }\end{array}$ & 16 & $\begin{array}{l}1.38 \times 10^{-2} \\
(50.41 \%) \\
1.38 \times 10^{-2} \\
(72.32 \%) \\
2.18 \times 10^{-2} \\
(36.14 \%)\end{array}$ & $\begin{array}{l}2.31 \times 10^{-1} \\
(81.73 \%) \\
2.83 \times 10^{-1} \\
(117.14 \%) \\
2.49 \times 10^{-1} \\
(64.67 \%)\end{array}$ & $\begin{array}{l}2.63 \times 10^{-2} \\
(25.83 \%) \\
3.14 \times 10^{-2} \\
(31.05 \%) \\
3.63 \times 10^{-2} \\
(20.15 \%)\end{array}$ & $\begin{array}{l}4.62 \times 10^{-2} \\
(29.46 \%) \\
5.33 \times 10^{-2} \\
(34.42 \%) \\
3.51 \times 10^{-2} \\
(32.00 \%)\end{array}$ & $\begin{array}{l}1.38 \times 10^{-2} \\
(53.22 \%) \\
8.23 \times 10^{-3} \\
(129.50 \%) \\
1.40 \times 10^{-2} \\
(49.28 \%)\end{array}$ & $\begin{array}{l}2.31 \times 10^{-1} \\
(83.28 \%) \\
3.48 \times 10^{-1} \\
(191.24 \%) \\
6.46 \times 10^{-3} \\
(1281.75 \%)\end{array}$ & $\begin{array}{l}9.67 \times 10^{-2} \\
(0.00 \%) \\
1.79 \times 10^{-2} \\
(86.12 \%) \\
3.28 \times 10^{-2} \\
(41.18 \%)\end{array}$ & $\begin{array}{l}4.62 \times 10^{-2} \\
(32915.86 \%) \\
7.84 \times 10^{-3} \\
(287.91 \%) \\
1.63 \times 10^{-1} \\
(41.02 \%)\end{array}$ & $\begin{array}{l}-7.04 \times 10^{-2} \\
(0.00 \%) \\
2.67 \times 10^{-2} \\
(56.26 \%) \\
1.84 \times 10^{-2} \\
(292.39 \%)\end{array}$ & $\begin{array}{l}4.62 \times 10^{-2} \\
(40615.01 \%) \\
1.08 \times 10^{-1} \\
(61.07 \%) \\
1.65 \times 10^{-2} \\
(282.04 \%)\end{array}$ \\
\hline GMP & $\begin{array}{r}4 \\
16\end{array}$ & $\begin{array}{l}8.34 \times 10^{-3} \\
(14.74 \%) \\
1.14 \times 10^{-2} \\
(17.05 \%) \\
1.23 \times 10^{-2} \\
(30.59 \%)\end{array}$ & $\begin{array}{l}1.35 \times 10^{-1} \\
(33.65 \%) \\
1.70 \times 10^{-1} \\
(48.20 \%) \\
3.25 \times 10^{-1} \\
(96.26 \%)\end{array}$ & $\begin{array}{l}5.45 \times 10^{-2} \\
(20.37 \%) \\
1.47 \times 10^{-2} \\
(11.84 \%) \\
2.25 \times 10^{-2} \\
(16.28 \%)\end{array}$ & $\begin{array}{l}1.10 \times 10^{-2} \\
(39.17 \%) \\
6.50 \times 10^{-3} \\
(42.75 \%) \\
2.73 \times 10^{-2} \\
(53.13 \%)\end{array}$ & $\begin{array}{l}1.23 \times 10^{-3} \\
(207.51 \%) \\
2.46 \times 10^{-3} \\
(218.94 \%) \\
2.46 \times 10^{-3} \\
(218.94 \%)\end{array}$ & $\begin{array}{l}2.08 \times 10^{-3} \\
(9375.69 \%) \\
3.84 \times 10^{-2} \\
(923.31 \%) \\
3.84 \times 10^{-2} \\
(923.31 \%)\end{array}$ & $\begin{array}{l}4.59 \times 10^{-3} \\
(752.10 \%) \\
1.42 \times 10^{-2} \\
(47.34 \%) \\
1.42 \times 10^{-2} \\
(47.34 \%)\end{array}$ & $\begin{array}{l}1.03 \times 10^{-2} \\
(434.40 \%) \\
5.29 \times 10^{-3} \\
(117.81 \%) \\
5.29 \times 10^{-3} \\
(117.81 \%)\end{array}$ & $\begin{array}{l}8.48 \times 10^{-3} \\
(13.92 \%) \\
1.02 \times 10^{-2} \\
(84.25 \%) \\
1.02 \times 10^{-2} \\
(84.25 \%)\end{array}$ & $\begin{array}{l}1.71 \times 10^{-1} \\
(22.36 \%) \\
2.47 \times 10^{-1} \\
(76.91 \%) \\
2.47 \times 10^{-1} \\
(76.91 \%)\end{array}$ \\
\hline Lactoferrin & 16 & $\begin{array}{l}3.29 \times 10^{-3} \\
(33.33 \%) \\
1.72 \times 10^{-3} \\
(108.83 \%) \\
1.12 \times 10^{-2} \\
(21.62 \%)\end{array}$ & $\begin{array}{l}9.29 \times 10^{-3} \\
(116.79 \%) \\
4.71 \times 10^{-3} \\
(840.83 \%) \\
6.82 \times 10^{-3} \\
(106.34 \%)\end{array}$ & $\begin{array}{l}6.56 \times 10^{-3} \\
(22.04 \%) \\
1.84 \times 10^{-2} \\
(18.69 \%) \\
1.09 \times 10^{-2} \\
(27.34 \%)\end{array}$ & $\begin{array}{l}8.41 \times 10^{-2} \\
(20.04 \%) \\
4.39 \times 10^{-2} \\
(20.02 \%) \\
9.89 \times 10^{-2} \\
(36.44 \%)\end{array}$ & $\begin{array}{l}1.96 \times 10^{-3} \\
(113.21 \%) \\
-5.26 \times 10^{-3} \\
(-76.90 \%) \\
5.91 \times 10^{-3} \\
(110.58 \%)\end{array}$ & $\begin{array}{l}5.59 \times 10^{-3} \\
(576.31 \%) \\
5.86 \times 10^{-2} \\
(48295.13 \%) \\
1.35 \times 10^{-1} \\
(793076.09 \%)\end{array}$ & $\begin{array}{l}4.26 \times 10^{-3} \\
(132.50 \%) \\
2.20 \times 10^{-2} \\
(31.28 \%) \\
6.12 \times 10^{-3} \\
(133.68 \%)\end{array}$ & $\begin{array}{l}3.51 \times 10^{-2} \\
(122.87 \%) \\
4.49 \times 10^{-3} \\
(42.11 \%) \\
1.35 \times 10^{-1} \\
(620207.46 \%)\end{array}$ & $\begin{array}{l}3.73 \times 10^{-3} \\
(114.70 \%) \\
5.86 \times 10^{-2} \\
(9362.94 \%) \\
1.06 \times 10^{-2} \\
(24.68 \%)\end{array}$ & $\begin{array}{l}1.57 \times 10^{-1} \\
(95.28 \%) \\
5.05 \times 10^{-3} \\
(237.31 \%) \\
6.90 \times 10^{-3} \\
(93.73 \%)\end{array}$ \\
\hline
\end{tabular}

served (Fig. 2c). Again we observed a tendency for decreasing the mass released with increasing peptide molecular weight. However, this parameter response to temperature increase was dependent on the peptide: in WPC fraction and GMP, $M_{R}$ increased with temperature (Fig. 2c) (I and II) and lactoferrin, $M_{\infty, R_{1}}$ was constant (Fig. 2c) (III).
In a previous work, our group characterized the peptides used in this study and investigated the effect of their addition on the thermo-mechanical and microstructure properties of the obtained films (Table 2, Bourbon et al., 2011). Considering our previous results, the observed differences in $M_{\infty, R_{1}}$ behavior with temperature and peptide type, may be related with the film physical characteristics. 
(a)
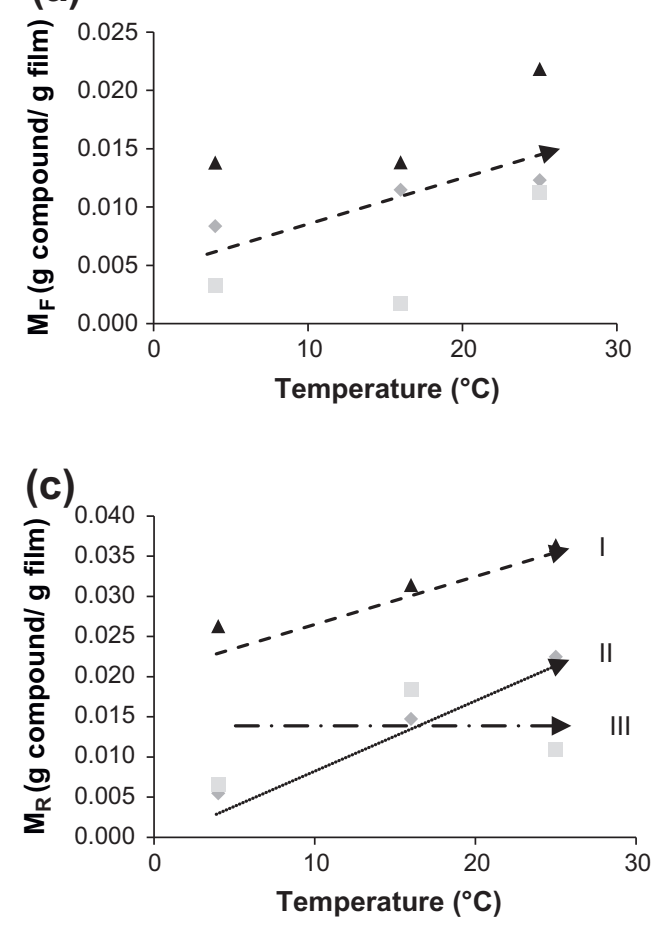

(b)
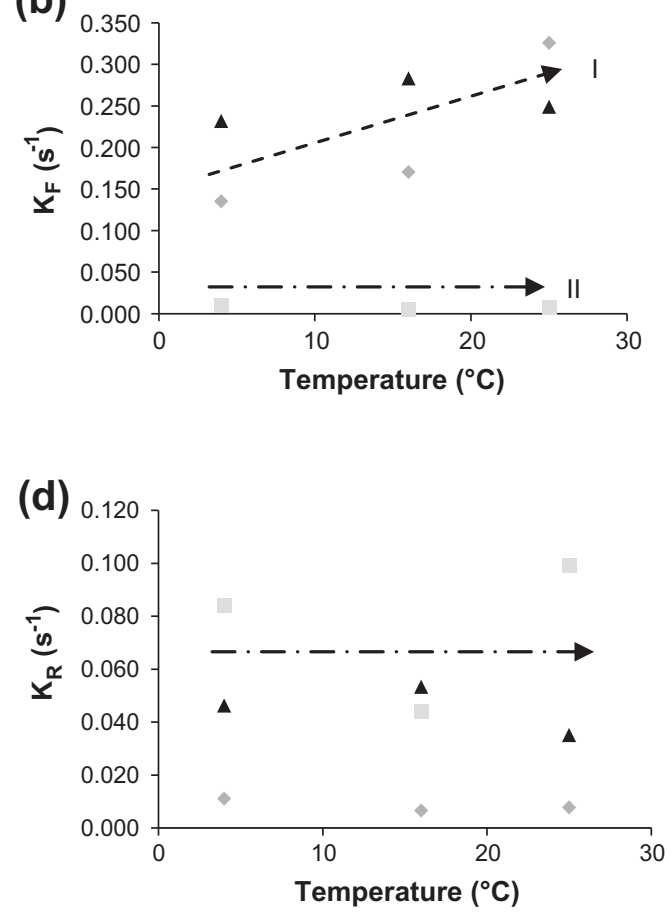

Fig. 2. Effect of bioactive compounds molecular weight on the superimposition model parameters: total mass released via Fick's transport $\left(M_{F}\right)$ and polymer relaxation $\left(M_{R}\right)$; fickian $\left(k_{F}\right)$ and relaxation $\left(k_{R}\right)$ rates of diffusion. $\mathbf{\Delta}$ Peptide fraction from WPC; $\downarrow$ GMP and $\mathbf{\square}$ lactoferrin. The arrows numbered I, II and III represent only the tendency of parameters behavior discussed in the text and do not contain any model information.

Table 2

Thermo-mechanical and microstructure properties of the chitosan films with bioactive compounds incorporated (results from Bourbon et al. (2011)).

\begin{tabular}{llllll}
\hline Film composition & $\mathrm{MW}^{\mathrm{a}}(\mathrm{kDa})$ & Film thickness $(\mathrm{mm})$ & $\mathrm{TS}^{\mathrm{b}}(\mathrm{MPa})$ & $E^{\mathrm{c}}(\%)$ & $\Delta_{m}{ }^{\mathrm{d}}\left(\mathrm{Jg}^{-1}\right)$ \\
\hline Peptide fraction from WPC & 8.67 & 0.186 & 7.36 & 75.77 & 29.61 \\
GMP & 20.30 & 0.177 & 7.90 & 72.42 & 26.26 \\
Lactoferrin & 79.25 & 0.147 & 2.17 & 100.78 & 40.26 \\
\hline
\end{tabular}

a $\mathrm{MW}$ - molecular weight.

b TS - tensile strength.

c $E$ - elongation at break.

d $\Delta h_{m}$ - specific enthalpy of melting.

e Evaluated by confocal laser microscopy.

Comparing the two films where a temperature dependence was observed (with GMP and WPC fraction), total mass released by relaxation of GMP (Fig. 2c) II) was more sensitive to temperature than the mass released by relaxation of the WPC fraction (Fig. 2c) I). This was somehow unexpected: since GMP has a higher molecular weight one could envisage lower temperature sensitivity, as observed in Fickian behavior (see discussion above).

Moreover, from Table 2, we see these two films do not have significantly different properties: Elongation at Break, Tensile Strength, Crystallinity and film thickness are identical. However we could observe by confocal laser scanning microscopy (Bourbon et al., 2011) that GMP is dispersed in the film homogeneously while WPC fraction is heterogeneously dispersed in the matrix. This structural difference may influence the relaxation behavior and thus the mass released: the peptide that is heterogeneously dispersed (WPC fration) may be "trapped" in some regions of the polymeric system, thus minimizing temperature dependence of the transport phenomenon.

The total mass released via relaxation of lactoferrin, $M_{\infty, R_{1}}$, was constant with temperature (Fig. 2c) III), indicating this compound is interacting with the polymeric matrix in a totally different way in the studied temperature range. Previous results showed lactoferrin films were significantly different from the WPC and GMP films (Table 2). They were (i) thinner - maximizing the distance of the system to the equilibrium and thus promoting Case II transport; (ii) more crystalline - increasing the free volume (and thus mobility) on the amorphous part of the system (where the lactoferrin is dispersed); and (iii) more deformable (higher EB), favoring relaxation at even low temperatures.

This effect of the type of film did not only affect the mass released by relaxation, but also the percentage of peptide released from the film, which followed the same temperature and molecular weight tendencies. Overall, this percentage ranged from 14 to $92 \%$, showing great potential for developing products with different characteristics and reaction to environmental conditions.

The results obtained in this paper allow us to propose a simple mathematical model for describing bioactive compounds release from a bio-polymeric matrix. The model allows clarifying the transport mechanism, which is related with the polymeric matrix physical characteristics. 


\section{Conclusions}

The transport mechanism of bioactive compounds in chitosan films has been identified and quantified. The release of such compounds from chitosan films was successfully described by a simple mathematical model which accounts for both Fickian and Case II mass transport - i.e. anomalous behavior.

The model allowed clarifying the transport mechanism, which is related with the polymeric matrix's physical characteristics. In fact, it was possible to conclude that, in these cases, mass transport is affected by one main relaxation - i.e. molecular rearrangement due to swelling - of the chitosan matrix.

The mechanism of transport - effects of temperature and peptide size - was successfully correlated with physical properties of the chitosan films.

These results contribute to a deeper understanding of the phenomena involved in mass transport in hydrophilic bio-polymeric matrices and may be used e.g. in food and pharmaceutical applications for studies on shelf-life of products and of health issues upon food/drug consumption/ingestion.

\section{Acknowledgments}

This work was supported by Fundação para a Ciência e a Tecnologia through project PTDC/AGR/ALI/67194/2006. Authors Ana C. Pinheiro, Ana I. Bourbon and Mafalda A.C. Quintas gratefully acknowledge their Grants SFRH/BD/48120/2008, SFRH/BD/73178/ 2010 and SFRH/BPD/41715/2007, respectively.

\section{References}

Bailey, K., 1983. Physiological factors affecting drug toxicity. Regulatory Toxicology and Pharmacology 3 (4), 389-398.

Bates, D., Watts, D., 1988. Non-linear Regression Analysis and its Applications. John Wiley \& Sons, New York.

Bégin, A., Van Calsteren, M.-R., 1999. Antimicrobial films produced from chitosan. International Journal of Biological Macromolecules 26 (1), 63-67.

Berens, A.R., Hopfenberg, H.B., 1978. Diffusion and relaxation in glassy polymer powders. 2. Separation of diffusion and relaxation parameters. Polymer 19 (5), 489-496.

Bourbon, A.I., Pinheiro, A.C., Cerqueira, M.A., Rocha, C.M.R., Avides, M.C., Quintas, M.A.C., Vicente, A.A. 2011. Physico-chemical characterization of chitosan-based edible films incorporating bioactive compounds of different molecular weight Journal of Food Engineering 106 (2), 111-118

Brandao, T.R.S., Oliveira, F.A.R., Cunha, L.M., 2001. Design of experiments for improving the precision in the estimation of diffusion parameters unde isothermal and non-isothermal conditions. International Journal of Food Science and Technology 36 (3), 291-301.

Buonocore, G.G., Del Nobile, M.A., Panizza, A., Bove, S., Battaglia, G., Nicolais, L., 2003. Modeling the lysozyme release kinetics from antimicrobial films intended for food packaging applications. Journal of Food Science 68 (4), 1365-1370.

Crank, J., 1975. The Mathematics of Diffusion, second ed.. Clarendon Press, Oxford.

Del Nobile, M., Mensitieri, G., Netti, P.A., Nicolais, L., 1994. Anomalous diffusion in poly-ether-ether-ketone (PEEK). Chemical Engineering Science 49 (5), $633-$ 644.

Del Nobile, M.A., Conte, A., Incoronato, A.L., Panza, O., 2008. Antimicrobial efficacy and release kinetics of thymol from zein films. Journal of Food Engineering 89 (1), 57-63.

Faisant, N., Siepmann, J., Benoit, J.P., 2002. PLGA-based microparticles: elucidation of mechanisms and a new, simple mathematical model quantifying drug release. European Journal of Pharmaceutical Sciences 15 (4), 355-366.

Flores, S., Conte, A., Campos, C., Gerschenson, L., Del Nobile, M., 2007. Mass transport properties of tapioca-based active edible films. Journal of Food Engineering 81 (3), 580-586.

González-Chávez, S.A., Arévalo-Gallegos, S., Rascón-Cruz, O., 2009. Lactoferrin: structure, function and applications. International Journal of Antimicrobial Agents 33 (4), 301.e301-301.e308.

Hagman, J., Lorén, N., Hermansson, A.-M., 2010. Effect of gelatin gelation kinetics on probe diffusion determined by FRAP and rheology. Biomacromolecules 11 (12), 3359-3366.

Heirlings, L., Siró, I., Devlieghere, F., Van Bavel, E., Cool, P., De Meulenaer, B., Vansant, E.F., Debevere, J., 2004. Influence of polymer matrix and adsorption onto silica materials on the migration of $\alpha$-tocopherol into 95\% ethanol from active packaging. Food Additives and Contaminants 21 (11), 1125-1136.

Jain, R.A., 2000. The manufacturing techniques of various drug loaded biodegradable poly(lactide-co-glycolide) (PLGA) devices. Biomaterials 21 (23), 2475-2490.

Kakizawa, Y., Nishio, R., Hirano, T., Koshi, Y., Nukiwa, M., Koiwa, M., Michizoe, J., Ida, N., 2010. Controlled release of protein drugs from newly developed amphiphilic polymer-based microparticles composed of nanoparticles. Journal of Controlled Release 142 (1), 8-13.

Karbowiak, T., Hervet, H., Léger, L., Champion, D., Debeaufort, F., Voilley, A., 2006 Effect of plasticizers (water and glycerol) on the diffusion of a small molecule in ota-carrageenan biopolymer films for edible coating application. Biomacromolecules 7 (6), 2011-2019.

Liang, Y., Bowen, W.R., 2005. Correlation of the gradient diffusion coefficients of human lactoferrin with interparticle interactions validated by photon correlation spectroscopy. Journal of Colloid and Interface Science 284 (1), 157-166.

Liu, C.H., Kao, Y.H., Chen, S.C., Sokoloski, T.D., Sheu, M.T., 1995. In-vitro and in-vivo studies of the diclofenac sodium controlled-release matrix tablets. Journal of Pharmacy and Pharmacology 47 (5), 360-364.

Mullally, M.M., Meisel, H., FitzGerald, R.J., 1997. Angiotensin-I-converting enzyme inhibitory activities of gastric and pancreatic proteinase digests of whey proteins. International Dairy Journal 7 (5), 299-303.

Nakajima, K., Tamura, N., Kobayashi-Hattori, K., Yoshida, T., Hara-Kudo, Y., Ikedo, M., Sugita-Konishi, Y., Hattori, M., 2005. Prevention of Intestinal Infection by Glycomacropeptide. Bioscience, Biotechnology, and Biochemistry 69 (12) 2294-2301.

Ouattara, B., Simard, R.E., Piette, G., Bégin, A., Holley, R.A., 2000. diffusion of acetic and propionic acids from chitosan-based antimicrobial packaging films. Journal of Food Science 65 (5), 768-773.

Park, H.J., 1999. Development of advanced edible coatings for fruits. Trends in Food Science \& Technology 10 (8), 254-260.

Parveen, S., Sahoo, S., 2008. Polymeric nanoparticles for cancer therapy. Journal of Drug Targeting 16, 108-123.

Peppas, N.A., Sahlin, J.J., 1989. A simple equation for the description of solute release. III. Coupling of diffusion and relaxation. International Journal of Pharmaceutics 57 (2), 169-172.

Polakovic, M., Görner, T., Gref, R., Dellacherie, E., 1999. Lidocaine loaded biodegradable nanospheres: II. Modelling of drug release. Journal of Controlled Release 60 (2-3), 169-177.

Pranoto, Y., Rakshit, S.K., Salokhe, V.M., 2005. Enhancing antimicrobial activity of chitosan films by incorporating garlic oil, potassium sorbate and nisin. LWTFood Science and Technology 38 (8), 859-865.

Rathore, M.M., Kapuno, R., 2011. Engineering Heat Transfer, second ed.. Jones \& Bartlett Learning, London, UK.

Rojas-Graü, M.A., Oms-Oliu, G., Soliva-Fortuny, R., Martín-Belloso, O., 2009. The use of packaging techniques to maintain freshness in fresh-cut fruits and vegetables: a review. International Journal of Food Science \& Technology 44 (5), 875-889.

Sebti, I., Blanc, D., Carnet-Ripoche, A., Saurel, R., Coma, V., 2004. Experimental study and modeling of nisin diffusion in agarose gels. Journal of Food Engineering 63 (2), 185-190.

Shi, P., Zuo, Y., Zou, Q., Shen, J., Zhang, L., Li, Y., Morsi, Y.S., 2009. Improved properties of incorporated chitosan film with ethyl cellulose microspheres for controlled release. International Journal of Pharmaceutics 375 (1-2), 67-74.

Shu, X.Z., Zhu, K.J., Song, W., 2001. Novel pH-sensitive citrate cross-linked chitosan film for drug controlled release. International Journal of Pharmaceutics 212 (1) 19-28.

Siepmann, J., Streubel, A., Peppas, N.A., 2002. Understanding and predicting drug delivery from hydrophilic matrix tablets using the "sequential layer" model. Pharmaceutical Research 19 (3), 306-314.

Siripatrawan, U., Harte, B.R., 2010. Physical properties and antioxidant activity of an active film from chitosan incorporated with green tea extract. Food Hydrocolloids 24 (8), 770-775.

Siró, I., Fenyvesi, É., Szente, L., De Meulenaer, B., Devlieghere, F., Orgoványi, J., Sényi, J., Barta, J., 2006. Release of alpha-tocopherol from antioxidative low-density polyethylene film into fatty food simulant: influence of complexation in betacyclodextrin. Food Additives and Contaminants 23 (8), 845-853.

Souza, B.W.S., Cerqueira, M.A., Casariego, A., Lima, A.M.P., Teixeira, J.A., Vicente, A.A. 2009. Effect of moderate electric fields in the permeation properties of chitosan coatings. Food Hydrocolloids 23 (8), 2110-2115.

Thomä-Worringer, C., Sørensen, J., López-Fandiño, R., 2006. Health effects and technological features of caseinomacropeptide. International Dairy Journal 16 (11), 1324-1333.

Vesely, D., 2008. Diffusion of liquids in polymers. International Materials Reviews 53 (5), 299-315.

Visser, T., Wessling, M., 2007. When do sorption-induced relaxations in glassy polymers set in? Macromolecules 40 (14), 4992-5000.

Vrentas, J.S., Jarzebski, C.M., Duda, J.L., 1975. A Deborah number for diffusion in polymer-solvent systems. AIChE Journal 21 (5), 894-901. 